Original Article- Clinical Science

\title{
Ten-year changes of intraocular pressure in adults: the Liwan Eye Study
}

Xiaotong Han MD, ${ }^{1,2^{*}}$ Haifeng Zhao MD, ${ }^{1,3^{*}}$ Changfan Wu MD, ${ }^{4}$ Chi Liu MSc, ${ }^{5}$ William Yan MBBS, ${ }^{2}$ Yin Hu MD PhD ${ }^{1}$ and Mingguang He MD PhD ${ }^{1,2}$

* These two authors have made equal contributions.

1. State Key Laboratory of Ophthalmology, Zhongshan Ophthalmic Center, Sun Yat-sen University, Guangzhou, China

2. Centre for Eye Research Australia; Ophthalmology, Department of Surgery, University of Melbourne, Melbourne, Australia

3. Yichun Aier Eye Hospital, Yichun, Jiangxi Province, China

4. Department of Ophthalmology, Yijishan Hospital of Wannan Medical College, Wuhu, China

5. Guangzhou Healgoo Interactive Medical Technology Co. Ltd., Guangzhou, China

Correspondence: Prof. Mingguang He, Department of Preventive Ophthalmology, Zhongshan Ophthalmic Center, Guangzhou 510060, People's Republic of China.

Email: mingguang he@yahoo.com

Short running title: 10 -year intraocular pressure changes

Received 25 May 2018; accepted 4 August 2018

This is the author manuscript accepted for publication and has undergone full peer review but has not been through the copyediting, typesetting, pagination and proofreading process, which may lead to differences between this version and the Version of Record. Please cite this article as doi: $10.1111 /$ ceo.13372

This article is protected by copyright. All rights reserved. 
Conflict of interest: None

Funding sources: The study was supported by the Fundamental Research Funds of the State Key Laboratory in Ophthalmology, National Natural Science Foundation of China (81420108008 and 81570843 H1204), and Science and Technology Planning Project of Guangdong Province, China 2013B20400003. Prof. He receives support from the University of Melbourne at Research Accelerator Program and the CERA Foundation. The Centre for Eye Research Australia receives Operational Infrastructure Support from the Victorian State Government. The sponsor or funding organization had no role in the design or conduct of this research. 


\section{ABSTRACT}

Importance: Understanding the longitudinal intraocular pressure (IOP) changes and potential risk factors in adults is important for future glaucoma control in the aging society.

Background: Limited longitudinal studies exists in Asia investigating the longitudinal IOP changes and with varying results.

Design: Population-based cohort study.

Participants: 1405 baseline participants from the Liwan Eye Study.

Methods: All baseline participants were invited for the 10-year follow-up examination in 2013. IOP (by Tonopen), central corneal thickness (CCT, by ultrasound), refractive error (by autorefractor), blood pressure, height and weight were measured per standardized protocol, and the presence of hypertension or diabetes was collected by questionnaire. Follow-up examinations were conducted using the same equipment with proper calibration. Linear regression analysis was used to assess the association between IOP change and potential risk factors.

Main outcome measures: 10 -year IOP change.

Results: Of the 791 participants at the 10-year follow-up, IOP data were available for 602 participants with a mean age of 60.9 years (55.5\% female). The average IOP change over 10 years was an increase of $1.44 \mathrm{mmHg}$ ( $95 \%$ confidence interval, 1.12 to 1.75). Linear regression showed that 10 -year IOP change was not associated with baseline age, gender, body mass index (BMI), CCT, spherical equivalence (SE), hypertension or diabetes. However, it was positively associated with longitudinal increase of BMI when longitudinal changes of BMI and SE were included in the model $(\mathrm{P}<0.001)$.

Conclusions and relevance: We observed a small increase in IOP over 10 years in 
this adult Chinese population, which was positively related to the longitudinal change in BMI.

Keywords: glaucoma, intraocular pressure, age, longitudinal INTRODUCTION

Glaucoma is a leading cause of irreversible blindness, and it is estimated that the glaucoma population worldwide would increase to 111.0 million in $2040 .{ }^{1}$ As glaucoma mainly affects the elderly, reducing the occurrence of glaucoma poses a great challenge in both developing and developed countries in the aging society. ${ }^{2}$ Intraocular pressure (IOP) had been widely acknowledged as the most important modifiable risk factor for the development of glaucoma, but the reported age-related IOP change remains inconsistent. ${ }^{3}$ Population-based studies among Caucasian and African populations have mostly showed a positive association between IOP and age $^{4-6}$ while cross-sectional studies in Asian populations reported an inverse association. ${ }^{7-10}$ Whether this is due to true aging effect or cohort effect is still in contention.

Given that the intra-individual difference in IOP is smaller than the inter-individual difference, a long-term longitudinal study is most appropriate in design to investigate the association between aging and IOP. In current literature, limited longitudinal studies of IOP in Asian populations existed with Nomura et al. found a increasing trend in IOP with aging while Nakano et al. and two other longitudinal Korean studies reported a decresing trend. ${ }^{10-13}$ Therefore more population-based longitudinal studies are needed to investigate age-related IOP changes. China has the largest absolute number of glaucoma patients in the world, ${ }^{14}$ and to the best of our knowledge, no 
conclusion had been reached from population-based studies concerning the longitudinal trend in IOP changes in China.

Many factors have previously been reported to influence IOP. Greater corneal thickness (CCT) ${ }^{15,16}$ blood pressure (BP) ${ }^{17,18}$ and body mass index (BMI) ${ }^{18,19}$ were reported to be associated with a higher IOP. The presence of diabetes mellitus (DM) was also reported to be a risk factor for high IOP. ${ }^{20,21}$ As these evidence are mostly based on cross-sectional studies which cannot demonstrate temporal causation, it is valuable to evaluate their associations with IOP longitudinally. Association between refractive error and IOP was rarely reported in literature. ${ }^{22}$ Given the rising prevalence of myopia in recent decades, especially in China, it would be meaningful to investigate the effect of longitudinal refraction changes on IOP.

The purpose of this study was to report the 10-year IOP changes and associated risk factors in a population-based Chinese adult cohort.

\section{METHODS}

\section{Study Population}

The Liwan Eye Study is a population-based prospective longitudinal study in Southern China, the methodology in detail has been reported elsewhere. ${ }^{23}$ Briefly, residents aged 50 years or older in the Liwan District, Guangzhou City were identified and enrolled by clustered random sampling at baseline in 2003. A total of 1405 participants underwent baseline examination, and all were invited to attend the 5-year and 10-year follow-up examinations. Over the 10-year period, 330 (23.5\%) participants had deceased, $127(9.0 \%)$ refused follow-up examination and $157(11.2 \%)$ relocated out 
of the district and were lost to follow-up. The remaining 791 participants (response rate: $86.2 \%$ ) returned for follow-up examination in 2013. Follow-up examinations were conducted using the same equipment with proper calibration and the same standardized protocol. Only participants with available IOP data at both baseline and the 10-year follow-up were included in the current analysis. Participants who had been diagnosed with glaucoma or had undergone intraocular surgeries before baseline or during the follow-up were further excluded.

Ethics approval for the study was obtained from Zhongshan Ophthalmic Center Ethics Review Board. The study was observed the tenets of the Declaration of Helsinki and written informed consent was obtained from all participants.

\section{Procedures}

Both ocular and physical examinations were performed at baseline and follow-ups. IOP was measured with a handheld tonometer (Tonopen; Mentor, Norwell, Massachusetts, USA) by an experienced technician after local anesthesia $(0.4 \%$ Benoxil; Oxybuprocaine, Santen, Japan) and before pupil dilation. The mean of 3 consecutive measurements was recorded as the final value for each eye. The IOP was considered unmeasurable if a standard error of $<5 \%$ could not be achieved after 10 repeated sets of measurements, or if the participants were unable to cooperate. Automated refraction (ARK-30; Nidek Corp, Gamagori, Japan) was performed in both eyes separately without cycloplegia, and spherical equivalent (SE) was calculated as spherical $+1 / 2$ cylindrical power. Measurement was repeated if the standard error was more than $5 \%$ and the mean of 3 measurements was recorded as the final value. Central corneal thickness was measured only at baseline using an A-mode ultrasound pachymetry (Echoscan US1800; Nidek Corp.) with the probe perpendicular to the 
cornea at the pupil center.

Height and weight were measured with the participant standing upright wearing light clothes and without shoes. Height was measured to the closest centimeter $(\mathrm{cm})$ and weight to the closest kilogram (kg). BMI was calculated as weight in $\mathrm{kgs}$ divided by height in meters squared, and further divided into the normal weight and overweight subgroups using $25 \mathrm{~kg} / \mathrm{m}^{2}$ as the cut-off according to the WHO recommendation criteria. BP was measured only at follow-up examinations using an automatic upper arm blood pressure monitor (Omron, Hoofddorp, The Netherlands) by a trained nurse. A standard questionnaire was administered by a trained interviewer at each examination to collect personal information, surgical and medical history. Presence of glaucoma, hypertension or diabetes was defined based on a self-reported history of diagnosis or treatment.

\section{Statistical Analysis}

Statistical analysis was performed using a commercially available statistical software package (Stata 12.0; Stata Corp, College Station, Texas, USA). Data from the right eye were used for analysis. Ten-year IOP change was calculated by subtracting the baseline IOP value from follow-up IOP value. Independent $t$-test and Chi square test were used to compare the baseline characteristic of participants included and not-included in the current study. Paired t-test was used to assess the statistical significance on the longitudinal IOP changes in different age and gender subgroups. Linear regression analysis was used to assess the associations of potential risk factors with 10-year IOP changes. To avoid multicollinearity, mean arterial pressure (MAP) was used in the regression analysis, which calculated as one third of systolic BP plus

two thirds of diastolic BP. ${ }^{24}$ Multiple linear regression model 1 included all baseline 
variables including age, gender, BMI, CCT, SE, and the presence of hypertension and diabetes. Model 2 included the 10-year changes in BMI and SE as covariates, along with age, gender, CCT, the presence of diabetes at baseline and MAP at the 10-year follow-up. A p-values of less than 0.05 was considered statistically significant.

\section{RESULTS}

A total of 791 (56.3\% of baseline) participants attended the 10-year follow-up examination. Differences in baseline characteristics between follow-up participants and non-participants can be found in Supplementary Table 1. Of all follow-up participants, we further excluded 41 (5.2\%) participants without available IOP data and $148(18.7 \%)$ who had undergone intraocular surgery at baseline or 10-year follow-up. The remaining 602 participants (76.1\%) who attended the 10-year follow-up in 2013 were included in the current analysis with a mean (standard deviation, SD) baseline age of 60.9 (8.5) and $55.5 \%$ were female. When compared to participants who were excluded from this analysis, those included were significantly younger $(P<0.001)$ and had lower rate of diabetes $(P=0.001)$ at baseline (Table 1$)$.

Table 1: Baseline characteristics of participants included and not-included in this study

\begin{tabular}{lccc}
\hline & $\begin{array}{c}\text { Included } \\
\mathbf{( N = 6 0 2 )}\end{array}$ & $\begin{array}{c}\text { Not-included } \\
(\mathbf{N}=\mathbf{8 0 3})\end{array}$ & $\boldsymbol{P}$ Value \\
\hline Age, years & $60.9(8.5)$ & $68.6(9.8)$ & $<0.001$ \\
Female, \% & $55.5 \%$ & $57.0 \%$ & 0.59 \\
Intraocular pressure, $\mathbf{~ m m H g}$ & $15.3(3.0)$ & $15.1(3.2)$ & 0.29 \\
Body mass index, $\mathbf{~ k g / \mathbf { m } ^ { 2 }}$ & $23.7(3.1)$ & $23.4(3.6)$ & 0.12 \\
Central Corneal Thickness, $\mathbf{~ m m}$ & $0.51(0.03)$ & $0.51(0.03)$ & 0.44 \\
Spherical Equivalence, diopter & $-0.43(2.84)$ & $-0.49(2.70)$ & 0.70 \\
\hline
\end{tabular}




\begin{tabular}{lllc}
\hline Hypertension , \% & $40.1 \%$ & $42.9 \%$ & 0.33 \\
Diabetes, \% & $7.14 \%$ & $13.0 \%$ & 0.001 \\
\hline
\end{tabular}

Date were expressed as mean (standard deviation) or proportion.

Table 2 shows the age and gender-specific distributions of IOP at baseline and the 10-year follow-up. For men in the age group of 50-59, 60-69 and $\geq 70$ years, the mean (SD) change of IOP over 10 years were $1.75(3.4), 0.95(3.8)$ and $1.09(4.1) \mathrm{mmHg}$, respectively. While for women, the corresponding changes were 1.23(3.4), 1.19(3.3) and $2.53(6.5) \mathrm{mmHg}$, respectively. IOP at the 10 -year follow-up was significantly higher than baseline IOP, except for the male group aged above 60 years old. The overall IOP change was $1.44 \mathrm{mmHg}$ (95\% confidence interval [CI], 1.12 to 1.75 ) $(P<0.001)$ for the study population without a statistically significant gender difference. Distribution of the 10-year IOP change in different age, gender, hypertension and BMI subgroups are shown in Fig1. The corresponding 10-year mean (SD) changes in SE and BMI were $0.22(1.70)$ diopters and $-0.23(1.98) \mathrm{kg} / \mathrm{m}^{2}$, respectively.

Table 2: Age and gender-specific distribution of intraocular pressure at baseline and the 10-year follow up

\begin{tabular}{lcccc}
\hline & N & Baseline & $\begin{array}{c}\text { 10-year } \\
\text { follow up }\end{array}$ & $\begin{array}{c}\text { 10-year } \\
\text { change }\end{array}$ \\
\hline $\begin{array}{l}\text { Male } \\
\text { Age group(years) }\end{array}$ & & & & \\
$\quad 50-59$ & 138 & $15.1(3.1)$ & $16.9(2.8)$ & $1.75(3.4) \dagger$ \\
$60-69$ & 83 & $15.3(3.6)$ & $16.3(3.0)$ & $0.95(3.8)$ \\
$\quad 70$ & 47 & $15.6(2.8)$ & $16.7(3.7)$ & $1.09(4.1)$ \\
$\quad$ Total & 268 & $15.3(3.2)$ & $16.6(3.1)$ & $1.39(3.6) \dagger$ \\
$\begin{array}{l}\text { Female } \\
\text { Age group(years) }\end{array}$ & & & & \\
$\quad 50-59$ & 173 & $15.6(2.7)$ & $16.9(2.7)$ & $1.23(3.4) \dagger$ \\
& & & &
\end{tabular}




\begin{tabular}{lclll}
$60-69$ & 95 & $15.4(3.2)$ & $16.5(3.0)$ & $1.19(3.3)^{\ddagger}$ \\
$\geq 70$ & 66 & $14.6(2.9)$ & $17.2(5.8)$ & $2.53(6.5)^{\ddagger}$ \\
$\quad$ Total & 334 & $15.4(2.9)$ & $16.8(3.6)$ & $1.48(4.2)^{\dagger}$ \\
All & & & & \\
Age group (years) & & & & \\
$50-59$ & 311 & $15.4(2.9)$ & $16.9(2.8)$ & $1.46(3.4){ }^{\dagger}$ \\
$60-69$ & 178 & $15.3(3.4)$ & $16.4(3.0)$ & $1.08(3.5)^{\ddagger}$ \\
$\geq 70$ & 113 & $15.0(2.9)$ & $17.0(5.1)$ & $1.93(5.6)^{\dagger}$ \\
$\quad$ Total & 602 & $15.3(3.0)$ & $16.8(3.4)$ & $1.44(3.9) \dagger$ \\
\hline
\end{tabular}

Data are presented as number or mean (standard deviation);

$+\mathrm{P}<0.001, \neq \mathrm{P}<0.05$, comparison of baseline and 10-year follow-up intraocular pressure using paired $t$ test

Figure 1: 10-year change of intraocular pressure in different population subgroup
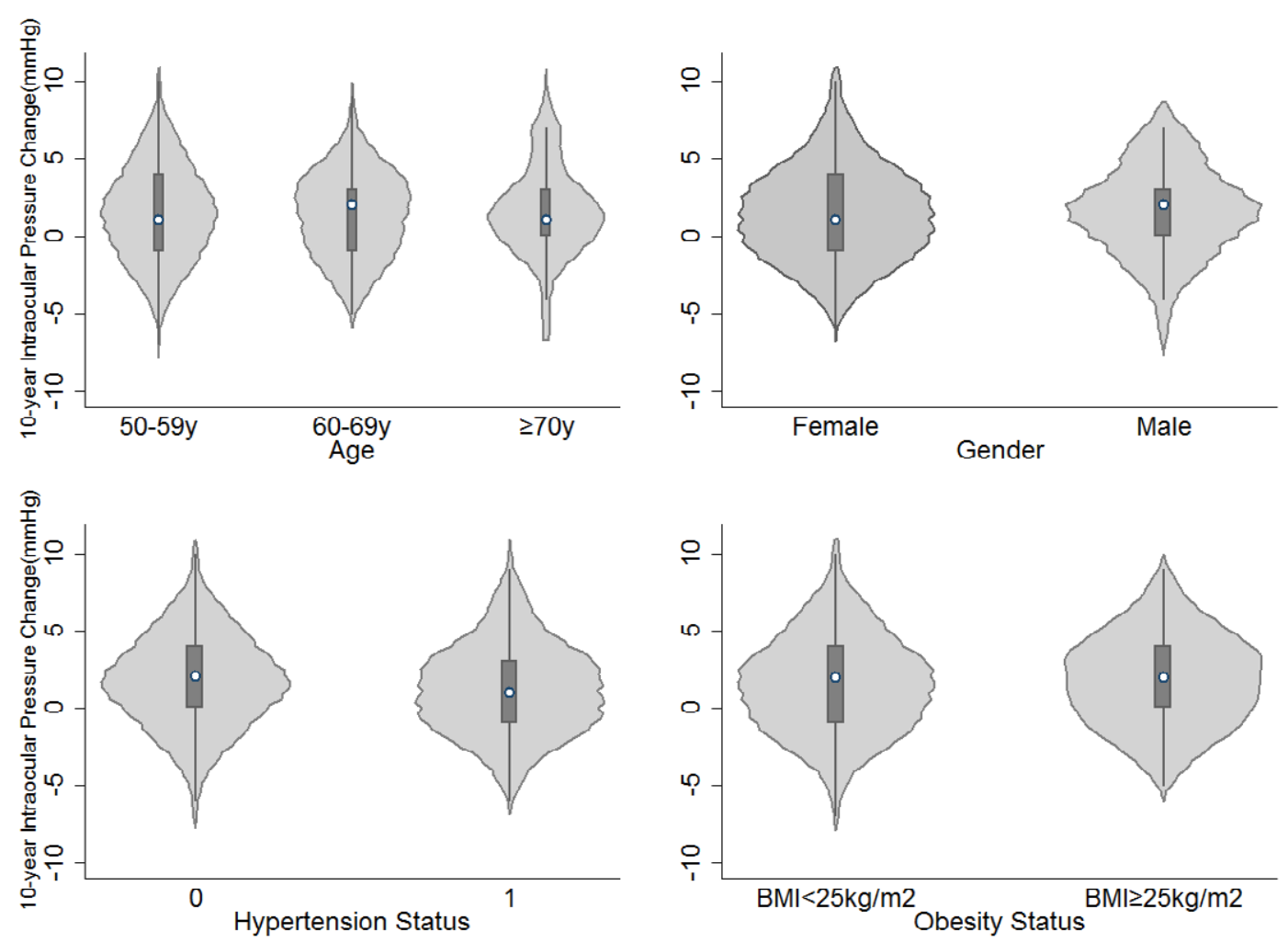
Univariate linear regression analysis showed that 10 -year changes in $B M I(P=0.001)$ and MAP at the 10-year follow-up $(P=0.002)$ were positively associated with the 10-year IOP changes. In the multiple linear regression model 1 , the 10-year IOP change was not associated with age, gender, BMI, CCT, SE, hypertension or diabetes when the baseline characteristics were included. However, in model 2, the 10-year IOP change was significantly associated with 10 -year changes in BMI $(P<0.001)$, but not with other variables when longitudinal changes of BMI and SE and MAP at the 10-year follow-up were included. (Table 3). 
Table 3: Associations of potential risk factors with 10-year changes in intraocular pressure $(\mathrm{mmHg})$

\begin{tabular}{|c|c|c|c|c|c|c|}
\hline \multirow[b]{3}{*}{ Factors } & \multirow{2}{*}{\multicolumn{2}{|c|}{ Univariate analysis }} & \multicolumn{4}{|c|}{ Multiple regression analysis } \\
\hline & & & \multicolumn{2}{|c|}{ Model 1} & \multicolumn{2}{|l|}{ Model2 } \\
\hline & $\begin{array}{c}\text { Coefficient } \\
(95 \% \mathrm{CI})\end{array}$ & $\begin{array}{c}P \\
\text { Value } \\
\end{array}$ & $\begin{array}{c}\text { Coefficient } \\
(95 \% \mathrm{CI})\end{array}$ & P Value & $\begin{array}{c}\text { Coefficient } \\
(95 \% \mathrm{CI})\end{array}$ & P Value \\
\hline \multirow{2}{*}{ Baseline age, years } & $0.003(-0.03$ to & 0.88 & $0.00(-0.05$ to & & $-0.03(-0.07$ to 0.02$)$ & \\
\hline & $0.04)$ & & $0.05)$ & 1.00 & & 0.29 \\
\hline \multirow{2}{*}{ Gender, } & $-0.09(-0.72$ to & 0.79 & $-0.23(-1.04$ to & & $0.06(-0.65$ to 0.78$)$ & \\
\hline & $0.55)$ & & $0.59)$ & 0.58 & & 0.86 \\
\hline \multirow{2}{*}{ Baseline BMI, $\mathbf{k g} / \mathbf{m}^{2}$} & $-0.02(-0.15$ to & 0.75 & $-0.01(-0.15$ to & & - & \\
\hline & $0.11)$ & & $0.13)$ & 0.91 & & - \\
\hline \multirow{2}{*}{ Baseline CCT, mm } & $2.17(-9.22$ to & 0.71 & $2.04(-12.40$ to & & $7.61(-5.14$ to 20.36$)$ & \\
\hline & 13.6) & & 16.48) & 0.78 & & 0.24 \\
\hline \multirow{2}{*}{ Baseline SE, diopter } & $0.04(-0.08$ to & 0.54 & $0.04(-0.10$ to & & - & \\
\hline & $0.15)$ & & $0.18)$ & 0.58 & & - \\
\hline \multirow{2}{*}{$\begin{array}{l}\text { Baseline hypertension, } \\
\text { yes }\end{array}$} & $-0.49(-1.15$ to & 0.14 & $-0.69(-1.58$ to & & - & \\
\hline & $0.16)$ & & $0.20)$ & 0.13 & & - \\
\hline \multirow{2}{*}{ Baseline diabetes, yes } & $-0.09(-1.34$ to & 0.89 & $0.12(-1.60$ to & & $0.42(-0.99$ to 1.83$)$ & \\
\hline & 1.16) & & 1.84) & 0.89 & & 0.56 \\
\hline \multirow{2}{*}{$\begin{array}{l}10 \text { year change in BMI, } \\
\mathrm{kg} / \mathrm{m}^{2}\end{array}$} & $0.28(0.11$ to & 0.001 & - & & $0.33(0.15$ to 0.52$)$ & \\
\hline & $0.45)$ & & & - & & $<0.001$ \\
\hline
\end{tabular}




$\begin{array}{lcccc}\mathbf{1 0} \text { year change in SE, } & -0.03(-0.20 \text { to } & 0.75 & - & -0.13(-0.35 \text { to } 0.10) \\ \text { diopter } & 0.15) & & - & 0.28 \\ \text { MAP at } 2013 & 0.03(0.01 \text { to } & 0.002 & - & 0.01(-0.01 \text { to } 0.04) \\ \text { follow-up, } \mathbf{m m H g} & 0.06) & & & 0.26\end{array}$

BMI: body mass index; CCT: central corneal thickness; SE: spherical equivalent; MAP: mean arterial pressure; CI: confidence interval.

Model 1 included baseline age, gender, baseline BMI, baseline CCT, baseline SE, baseline hypertension and baseline diabetes status.

Model 2 include baseline age, gender, baseline CCT, baseline diabetes status, 10-year BMI change, 10-year SE change and MAP at the 2013 follow-up. 


\section{DISCUSSION}

In this population-based prospective adult Chinese cohort, we identified a small increase in IOP with age in both males and females over 10 years. The population-based design, recording of IOP measurements using Tonopen, an applanation tonometer at both baseline and follow-up visit, and the 10-year long follow-up period were all considered strengths to the present study.

Mean IOP reported in our study $(15.3 \pm 3.0 \mathrm{mmHg}$ at baseline) was similar to that reported in other studies based on Chinese populations $(15.6 \pm 3.0 \mathrm{mmHg}$ in Beijing and $15.3 \pm 2.3 \mathrm{mmHg}$ in Guangzhou, using a non-contact pneumotonometer), ${ }^{18,25}$ and higher that reported in Japan ( $11.9 \pm 2.5 \mathrm{mmHg}$, using a non-contact tonometer) and Korea $\left(13.6 \pm 2.5 \mathrm{mmHg}\right.$, using automated non-contact tomometers). ${ }^{11,13}$ This discrepancy on IOP distribution may be attributable to ethnicity and different methods of tonometry are used. ${ }^{26}$ In a cross-sectional analysis of all baseline participants of this cohort, ${ }^{27}$ age was found to be negatively associated with IOP after adjusting for age and gender, but no longer significantly associated with IOP in the fully-adjusted model. Greater BMI and CCT, as well as self-reported hypertension were associated with a higher IOP in the baseline analysis, which was consistent with other cross-sectional studies in the literature. ${ }^{15-17}$

In the current longitudinal analysis, IOP at the 10 -year follow-up visit was significantly higher than IOP at baseline, though the difference was small. Interestingly, we had identified similar results based on another longitudinal cohort of adult population in Southern China, apparent reduction in IOP with age in cross-sectional analysis and an increase of $0.43 \mathrm{mmHg}(95 \% \mathrm{CI}, 0.36$ to 0.50$)$ in IOP 
over 5 years. ${ }^{22,25}$ This pattern of change suggests that an increase of IOP is the authentic pattern of IOP change with aging, whereas the observed IOP reduction with age in cross-sectional analysis is likely due to cohort effect, for example, the younger birth cohorts have higher IOP in comparison to the older cohorts. In the existing literature, longitudinal studies on age-related IOP changes have mainly been based on Caucasian and African populations, and reported an overall increasing trend of IOP with age. ${ }^{4,5}$ Limited longitudinal studies have been conducted in East Asian populations, and these had furthermore presented conflicting results. Nomura et al. reported that IOP increased significantly with aging in both males and females in an 8 year follow-up, which is consistent with our findings. ${ }^{11}$ In contrast, Nakano et al. found a decrease in IOP over 10 years in a group of healthy Japanese male aircraft crew members. ${ }^{12}$ Baek et al. reported a negative association between IOP and age in their longitudinal analysis. ${ }^{10} \mathrm{~A}$ longitudinal Korean study reported an average of $-0.065 \mathrm{mmHg}$ change of IOP per year based on a large cohort, following up for 8 years. ${ }^{13}$ The Singapore Malay Eye Study reported a reduced IOP with normal aging in South East Asians. ${ }^{28}$ The Beijing Eye Study reported a mean change in IOP of $-1.25 \pm 2.26 \mathrm{mmHg}$ over 5 years, but did not assess the longitudinal trend. ${ }^{18}$ The difference in the above findings could be partly explained by difference in ethnicity or the difference in the change pattern of risk factors associated with IOP, such as BP and BMI. ${ }^{29}$ It is unclear if the natural history of IOP were similar across different Asian population groups, as Japanese were more likely to develop normal tension glaucoma while Chinese were more prone to have primary angle-closure glaucoma. ${ }^{30}$ Based on the current evidence, we suggest there is slight increase in IOP over time in adult Chinese.

Despite that higher BMI, hypertension, and greater CCT were found to be positively 
associated with IOP in our baseline analysis, ${ }^{27}$ only change in BMI was significantly associated with the 10-year longitudinal IOP change, while associations with other baseline variables were no longer statistically significant. Higher BMI could contribute to an increase in IOP by increased blood viscosity, epi-scleral venous pressure and increased orbital tissue pressure mechanisms. ${ }^{31}$ Multiple previous studies, either cross-sectional or longitudinal in design, had reported that a higher BMI was associated with a higher risk of glaucoma. ${ }^{18,22,32}$ The EPIC-Norfolk Eye Study also found that higher BMI was related to a thinner retinal nerve fiber layer. ${ }^{16}$ However, data from the Nurses' Health Study and the Health Professionals Follow-up Study showed that women with a higher BMI had a lower risk of primary open angle glaucoma. ${ }^{33}$ Based on our findings and other related longitudinal studies in China, ${ }^{18,22,25}$ we suggest that higher BMI could lead to an increase in IOP in Chinese population, and this could be part of reason that younger generations had higher IOP compared to the elderly in cross-sectional analysis.

A consistent positive relationship between hypertension and IOP had been reported in literature. ${ }^{17,28}$ Higher BP may increase IOP in a physiological way by increasing capillary pressure and choroidal volume. ${ }^{34}$ In the present study, we were unable to assess the relationship between 10-year BP changes and 10-year IOP changes as BP was not directly measured at baseline. However, given MAP at the 10-year follow-up was positively associated with IOP change in our univariate longitudinal analysis, we speculate that an increase in BP may also result in an increased IOP. Association between sex and IOP had been reported with inconsistent results. There was no gender difference in IOP distribution and 10-year IOP change in our study, which is supported by the Framingham Eye Study and other previous studies. ${ }^{8,35}$ The Kangbuk Samsung Health Study found females had a lower IOP compared to males 
and the yearly decrease in IOP was also smaller in females. ${ }^{36}$ Other studies such as the Beaver Dam Eye study and the Barbados Eye Study have found males to have a lower IOP. ${ }^{4,37}$ The gender difference is suggested to be mediated by hormonal differences and cardiovascular risk factors. ${ }^{13}$ Further research is needed to better understand the mechanisms between gender and IOP association. In addition, CCT was related to baseline IOP but not longitudinal IOP change in our analysis, perhaps due to that there was only minimal change in CCT over time in adults. Previous studies had reported a positive association between diabetes and IOP, but not consistently, ${ }^{28,38}$ we did not observe any significant associations between IOP and baseline diabetes status. Recall bias could be a potential reason for the lack of association between IOP and baseline diabetes or hypertension.

Associations between refractive error and IOP were less reported. We found that a myopic refractive change was related to increased IOP in the Lingtou Eye Cohort Study, ${ }^{22}$ while no associations were found in the current analysis. This could be due to the difference in age distribution in these two cohorts, as the Korea National Health and Nutrition Examination Survey reported that higher IOP was associated with myopic refractive error in young and middle-age group, but not in the older age group. ${ }^{39}$ The higher myopia prevalence and greater tensile strains in the younger generations could be part of the reason, and more studies are needed to investigate the effect of refractive error on IOP change for better understanding the glaucoma trend in the myopia epidemic society.

With more than $3 \%$ of the population suffering from glaucoma and a population of 1.3 billion, China is faced with a major health challenge in glaucoma prevention and control. ${ }^{40}$ To the best of our knowledge, our study was the only population-based 
study reporting a 10-year longitudinal IOP changes in China. Limitations of this study included a relatively low follow-up rate (72.9\%) and the inability to assess the relationship between longitudinal BP changes with IOP changes. In addition, the IOP measurement was not performed at the same time of the day and the influence of diurnal fluctuations in IOP was not accounted for. However, this effect is likely neutralized by the large number of participants in the current study.

In conclusion, we identified a small increase in IOP over 10-year in an adult Chinese population, with increasing BMI as an important risk factor underlying longitudinal IOP increase. Further studies may seek to clarify the underlying mechanisms of this association and to present new evidence for IOP-related disease prevention strategies in aging populations. 


\section{REFERENCES}

1. Tham YC, Li X, Wong TY, Quigley HA, Aung T, Cheng CY. Global prevalence of glaucoma and projections of glaucoma burden through 2040: a systematic review and meta-analysis. Ophthalmology 2014; 121: 2081-90.

2. Guedes G, Tsai JC, Loewen NA. Glaucoma and aging. Curr Aging Sci 2011; 4: 110-7.

3. Naito T, Yoshikawa K, Mizoue S et al. Relationship between progression of visual field defect and intraocular pressure in primary open-angle glaucoma. Clinical ophthalmology 2015; 9: 1373-8.

4. Klein $\mathrm{BE}$, Klein $\mathrm{R}$, Linton KL. Intraocular pressure in an American community. The Beaver Dam Eye Study. Investigative ophthalmology \& visual science 1992; 33: 2224-8.

5. Wu SY, Nemesure B, Hennis A, Leske MC, Barbados Eye Studies G. Nine-year changes in intraocular pressure: the Barbados Eye Studies. Archives of ophthalmology 2006; 124: 1631-6.

6. Rochtchina $E$, Mitchell $P$, Wang JJ. Relationship between age and intraocular pressure: the Blue Mountains Eye Study. Clinical \& experimental ophthalmology 2002; 30: 173-5.

7. Lin HY, Hsu WM, Chou P et al. Intraocular pressure measured with a noncontact tonometer in an elderly Chinese population: the Shihpai Eye Study. Archives of ophthalmology 2005; 123: 381-6.

8. Fukuoka $S$, Aihara $M$, Iwase $A$, Araie $M$. Intraocular pressure in an ophthalmologically normal Japanese population. Acta ophthalmologica 2008; 86: 434-9.

9. Lee MK, Cho SI, Kim $\mathrm{H}$ et al. Epidemiologic characteristics of intraocular 
pressure in the Korean and Mongolian populations: the Healthy Twin and the GENDISCAN study. Ophthalmology 2012; 119: 450-7.

10. Baek SU, Kee C, Suh W. Longitudinal analysis of age-related changes in intraocular pressure in South Korea. Eye (Lond) 2015; 29: 625-9.

11. Nomura $\mathrm{H}$, Shimokata $\mathrm{H}$, Ando F, Miyake $\mathrm{Y}$, Kuzuya F. Age-related changes in intraocular pressure in a large Japanese population: a cross-sectional and longitudinal study. Ophthalmology 1999; 106: 2016-22.

12. Nakano T, Tatemichi M, Miura Y, Sugita M, Kitahara K. Long-term physiologic changes of intraocular pressure: a 10-year longitudinal analysis in young and middle-aged Japanese men. Ophthalmology 2005; 112: 609-16.

13. Zhao D, Kim MH, Pastor-Barriuso R et al. A Longitudinal Study of Association between Adiposity Markers and Intraocular Pressure: The Kangbuk Samsung Health Study. PloS one 2016; 11: e0146057.

14. Quigley HA, Broman AT. The number of people with glaucoma worldwide in 2010 and 2020. The British journal of ophthalmology 2006; 90: 262-7.

15. Wong $T$, Wong TY, Foster PJ et al. The relationship of intraocular pressure with age, systolic blood pressure, and central corneal thickness in an asian population. Investigative ophthalmology \& visual science 2009; 50: 4097-102.

16. Foster PJ, Broadway DC, Garway-Heath DF et al. Intraocular pressure and corneal biomechanics in an adult British population: the EPIC-Norfolk eye study. Investigative ophthalmology \& visual science 2011; 52: 8179-85.

17. Yokomichi $\mathrm{H}$, Kashiwagi $\mathrm{K}$, Kitamura $\mathrm{K}$ et al. Evaluation of the associations between changes in intraocular pressure and metabolic syndrome parameters: a retrospective cohort study in Japan. BMJ open 2016; 6: e010360. 
18. Wang $\mathrm{YX}, \mathrm{Xu} \mathrm{L}$, Zhang $\mathrm{XH}$, You QS, Zhao L, Jonas JB. Five-year change in intraocular pressure associated with changes in arterial blood pressure and body mass index. The beijing eye study. PloS one 2013; 8: e77180.

19. Jang HD, Kim DH, Han K et al. Relationship Between Intraocular Pressure and Parameters of Obesity in Korean Adults: The 2008-2010 Korea National Health and Nutrition Examination Survey. Current eye research 2015; 40: 1008-17.

20. Zhao D, Cho J, Kim MH, Friedman DS, Guallar E. Diabetes, fasting glucose, and the risk of glaucoma: a meta-analysis. Ophthalmology 2015; 122: 72-8.

21. Khalaj M, Fereydooni S, Barikani A. Relationship between Diabetes and Intraocular Pressure. Acta medica Iranica 2015; 53: 363-8.

22. Han X, Yang $\mathrm{T}$, Zhang $\mathrm{J}$ et al. Longitudinal changes in intraocular pressure and association with systemic factors and refractive error: Lingtou Eye Cohort Study. BMJ open 2018; 8: e019416.

23. He M, Friedman DS, Ge J et al. Laser peripheral iridotomy in primary angle-closure suspects: biometric and gonioscopic outcomes: the Liwan Eye Study. Ophthalmology 2007; 114: 494-500.

24. Papaioannou TG, Protogerou $A D$, Vrachatis $D$ et al. Mean arterial pressure values calculated using seven different methods and their associations with target organ deterioration in a single-center study of 1878 individuals. Hypertens Res 2016; 39: 640-7.

25. Han X, Niu Y, Guo X, Hu Y, Yan W, He M. Age-Related Changes of Intraocular Pressure in Elderly People in Southern China: Lingtou Eye Cohort Study. PloS one 2016; 11: e0151766.

26. Carbonaro F, Andrew T, Mackey DA, Spector TD, Hammond CJ. Comparison of three methods of intraocular pressure measurement and their relation to 
central corneal thickness. Eye 2010; 24: 1165-70.

27. Wang $D$, Huang $W, L i Y$ et al. Intraocular pressure, central corneal thickness, and glaucoma in chinese adults: the liwan eye study. American journal of ophthalmology 2011; 152: 454-62 e1.

28. Chua J, Chee ML, Chin CWL et al. Inter-relationship between ageing, body mass index, diabetes, systemic blood pressure and intraocular pressure in Asians: 6-year longitudinal study. The British journal of ophthalmology 2018.

29. Chua J, Tham YC, Liao J et al. Ethnic differences of intraocular pressure and central corneal thickness: the Singapore Epidemiology of Eye Diseases study. Ophthalmology 2014; 121: 2013-22.

30. Chan EW, Li X, Tham YC et al. Glaucoma in Asia: regional prevalence variations and future projections. The British journal of ophthalmology 2016; 100: 78-85.

31. Mori K, Ando F, Nomura H, Sato $Y$, Shimokata H. Relationship between intraocular pressure and obesity in Japan. International journal of epidemiology 2000; 29: 661-6.

32. Kawase K, Tomidokoro A, Araie $M$ et al. Ocular and systemic factors related to intraocular pressure in Japanese adults: the Tajimi study. The British journal of ophthalmology 2008; 92: 1175-9.

33. Pasquale LR, Willett WC, Rosner BA, Kang JH. Anthropometric measures and their relation to incident primary open-angle glaucoma. Ophthalmology2010; 117: $1521-9$.

34. Klein $B E$, Klein $R$, Knudtson MD. Intraocular pressure and systemic blood pressure: longitudinal perspective: the Beaver Dam Eye Study. The British journal of ophthalmology 2005; 89: 284-7.

35. Kahn HA, Leibowitz HM, Ganley JP et al. The Framingham Eye Study. I. 
Outline and major prevalence findings. American journal of epidemiology 1977; 106: 17-32.

36. Zhao D, Kim MH, Pastor-Barriuso R et al. A longitudinal study of age-related changes in intraocular pressure: the Kangbuk Samsung Health Study. Investigative ophthalmology \& visual science 2014; 55: 6244-50.

37. Leske MC, Connell AM, Wu SY, Hyman L, Schachat AP. Distribution of intraocular pressure. The Barbados Eye Study. Archives of ophthalmology 1997; 115: 1051-7.

38. Hennis A, Wu SY, Nemesure B, Leske MC, Barbados Eye Studies G. Hypertension, diabetes, and longitudinal changes in intraocular pressure. Ophthalmology 2003; 110: 908-14.

39. Choi JA, Han K, Park YM, Park CK. Age-related association of refractive error with intraocular pressure in the Korea National Health and Nutrition Examination Survey. PloS one 2014; 9: e111879.

40. Chiu SL, Chu CL, Muo CH, Chen CL, Lan SJ. The Prevalence and the Incidence of Diagnosed Open-Angle Glaucoma and Diagnosed Angle-Closure Glaucoma: Changes From 2001 to 2010. Journal of glaucoma 2016. 

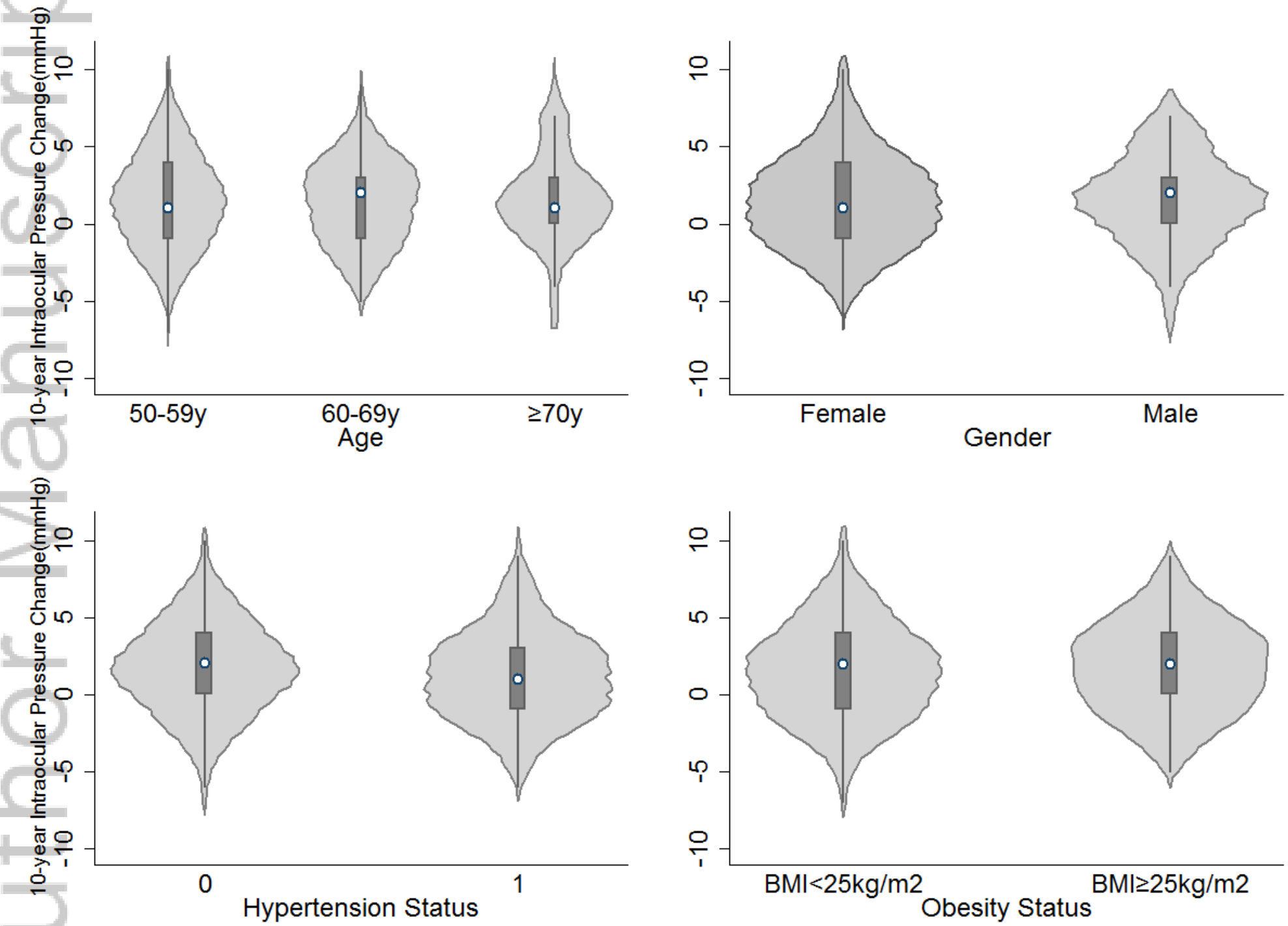

fig.png

This article is protected by copyright. All rights reserved. 


\section{University Library}

\section{- M M N E R VA A gateway to Melbourne's research publications}

Minerva Access is the Institutional Repository of The University of Melbourne

Author/s:

Han, X;Zhao, H;Wu, C;Liu, C;Yan, W;Hu, Y;He, M

Title:

Ten-year changes of intraocular pressure in adults: the Liwan Eye Study

Date:

2019-01-01

Citation:

Han, X., Zhao, H., Wu, C., Liu, C., Yan, W., Hu, Y. \& He, M. (2019). Ten-year changes of intraocular pressure in adults: the Liwan Eye Study. CLINICAL AND EXPERIMENTAL OPHTHALMOLOGY, 47 (1), pp.41-48. https://doi.org/10.1111/ceo.13372.

Persistent Link:

http://hdl.handle.net/11343/284344 